\title{
An evaluation of Panicum maximum cv. Gatton: 1. The effect of stocking rate and period of absence on the production of sheep
}

\author{
E. A. Relling, W. A. van Niekerk", R. J. Coertze and N.F.G. Rethman ${ }^{1}$ \\ Department of Animal and Wildlife Science, University of Pretoria, Pretoria 0002, South Africa \\ ${ }^{1}$ Department of Plant Production \& Soil Science, University of Pretoria, Pretoria 0002, South Africa
}

\begin{abstract}
The aim of this study was to evaluate the livestock production potential of Panicum maximum cv. Gatton cultivated under dry-land conditions and grazed at various stocking rates after various periods of re-growth. Treatments included a high stocking rate, fast rotation treatment (A), a medium stocking rate, medium rotation treatment (B) and a low stocking rate, long rotation treatment $(\mathrm{C})$. The initial availability of dry matter differed between treatments and was lowest for treatment $\mathrm{A}$ and highest for treatment $\mathrm{C}$. The same trend was observed for terminal availability of dry matter. The initial leaf:stem ratio did not differ between treatments A and B, but was lower for treatment $\mathrm{C}$. The terminal ratio did not differ between treatments $\mathrm{A}$ and $\mathrm{C}$ but was higher for treatment $\mathrm{B}$. Pasture height differed between treatments and was lowest for treatment $\mathrm{A}$ and highest for treatment $\mathrm{C}$ both at the beginning and end of the period. The sheep subject to treatment $C$ had the highest average daily gain and there was no difference between treatments A and B. Although treatment B resulted in the best individual performance, the highest stocking rate yielded the highest livestock production per ha.
\end{abstract}

Keywords: Panicum maximum, stocking rate, nutrition, sheep, ruminant.

\#Author to whom correspondence should be addressed: e-mail: wvniekerk@ postino.up.ac.za

\section{Introduction}

The study of tropical pasture systems is important to ensure that new pasture varieties are nutritionally equal to or superior to those already available, and to determine pasture management protocols for maximum or optimum production per animal or per unit area. Grazing trials are the most reliable methods of determining the quality of new varieties or the effect of management practices on pasture quality or animal production. Results from such trials should relate to practical conditions and can be presented in a way readily understood by industry. Grazing trials are, however, expensive and long-term by nature and can only be used to study a few of the most important problems (Minson, 1971).

The aim of this study was to evaluate the potential of Panicum maximum cv. Gatton for livestock production grazed at various stocking rates and after different periods of re-growth. The study was conducted to determine the best pasture management for optimum production per animal or per hectare.

Livestock production from pasture is an integrated measure of the quality and quantity of nutrients consumed which varies according to the quantity and quality of forage on offer (Heitschmidt et al., 1990). The hypothesis investigated in this trial was that the performance of individual sheep and production per hectare would be affected by stocking rate. Stocking rate would theoretically have such an effect because the stocking density and period of absence, and hence relative maturity of pasture on offer, would effect available pasture, competition between animals, quality of material on offer, quality of material selected and the opportunity for selective grazing.

\section{Materials and methods}

The study was conducted at the Hatfield Experimental Farm of the University of Pretoria. The site, situated at $28.11^{\circ} \mathrm{E}, 25.44^{\circ} \mathrm{S}$, is $1372 \mathrm{~m}$ above sea level. The site has an average annual rainfall of $674 \mathrm{~mm}$ with a dry autumn and winter. The average temperature and rainfall measured at the site during the experimental period is presented in Table 1.

The Panicum maximum cv. Gatton pasture was established two years before the trial which was conducted over a period of 84 days. The soil at the experimental site is classified as a sandy-loam, with a pH of 4.2, $\mathrm{P}$ content of $29 \mathrm{mg} / \mathrm{kg}$, K content of $73 \mathrm{mg} / \mathrm{kg}$, Ca content of $158 \mathrm{mg} / \mathrm{kg}$, Mg content of $38 \mathrm{mg} / \mathrm{kg}$ and Na content of $11 \mathrm{mg} / \mathrm{kg}$. The pasture was fertilised with $700 \mathrm{~kg}$ limestone ammonium nitrate $(28 \% \mathrm{~N})$ per ha in two equal dressings in spring 
and mid-summer, plus $300 \mathrm{~kg} \mathrm{KCl}$ per ha in a single spring application. The $\mathrm{N}$ fertilisation of $196 \mathrm{~kg} \mathrm{~N}$ per ha was relatively high. According to Pieterse et al. (1994) a positive response on growth rate and water use efficiency were observed with $\mathrm{N}$ fertilisation levels of up to $320 \mathrm{~kg} / \mathrm{ha}$.

Table 1 Rainfall $(\mathrm{mm})$ and average temperatures $\left({ }^{\circ} \mathrm{C}\right)$ for the first four months of 1990 at the experimental site

\begin{tabular}{lcccc}
\hline & January & February & March & April \\
\hline Rainfall $(\mathrm{mm})$ & 17.3 & 112.0 & 108.4 & 125.6 \\
Average minimum temperature $\left({ }^{\circ} \mathrm{C}\right)$ & 16.3 & 14.3 & 15.0 & 12.2 \\
Average maximum temperature $\left({ }^{\circ} \mathrm{C}\right)$ & 28.0 & 27.1 & 26.1 & 24.0 \\
\hline
\end{tabular}

Four-month-old Döhne-Merino wethers weighing 23-27.5 kg were randomly allocated to three groups of eight animals per treatment on 29 January 1990. Stocking rate was sequentially doubled between treatments (Table 2) with corresponding differences for period of absence. There were four grazing periods for treatment $\mathrm{A}$, two for treatment $\mathrm{B}$ and one for treatment $\mathrm{C}$. The animals had free access to clean drinking water throughout the experimental period. A 50:50 dicalciumphosphate - salt supplement was provided on an ad lib basis. Animals were treated against internal parasites and pulpy kidney disease, and given a Vitamin A supplement before the experiment started. The treatment against internal parasites was repeated every six weeks.

Table 2 Treatments used to evaluate the effect of different stocking rates on the production of sheep grazing $P$. maximum cv. Gatton

\begin{tabular}{llll}
\hline Treatment & $\mathrm{A}$ & $\mathrm{B}$ & $\mathrm{C}$ \\
\hline No. of sheep & 8 & 8 & 8 \\
Stocking rate (sheep/ha/grazing period) & 33 & 17 & 8 \\
Stocking density (sheep/ha) & 200 & 100 & 50 \\
Stocking rate (LSU/ha/grazing period)* & 3.15 & 1.62 & 0.76 \\
Stocking density (LSU/ha)* & 19.1 & 9.55 & 4.78 \\
No. of paddocks & 6 & 6 & 6 \\
Size of paddocks (ha) & 0.04 & 0.08 & 0.16 \\
Total area of treatment (ha) & 0.24 & 0.48 & 0.96 \\
Grazing period (days) & 3.5 & 7 & 14 \\
Period of absence (days) & 17.5 & 35 & 70 \\
Grazing cycle (days) & 21 & 42 & 84 \\
No of grazing cycles & 4 & 2 & 1 \\
\hline
\end{tabular}

* LSU: Livestock unit (Meissner et al., 1983)

Wethers were weighed at weekly intervals, without starvation, at a set time. Sampling for grazing observations was done on days 1 and 3 for treatment A, on days 1, 3 and 7 for treatment $B$ and on days 1, 3, 7, 10 and 14 for treatment C. Randomly stratified quadrats (five per replicate) within each treatment were clipped at an average height of $50 \mathrm{~mm}$ to determine dry material (DM) availability. The size of each quadrat was $2.5 \mathrm{~m}^{2}$. DM was determined after drying at $100^{\circ} \mathrm{C}$ for 24 hours. The average DM yield of the quadrats in each replicate (paddock) was determined and expressed as DM yield per ha (Waddington \& Cooke, 1971). Four sub-samples were taken from each quadrat for determination of leaf to stem ratio and DM content. Pasture height was measured with a pasture disc meter (Bransby \& Tainton, 1977). Availability of DM, percentage of leaf and stem and height of pasture were measured at the beginning and end of each grazing period.

An analysis of variance with the GLM model (Statistical Analysis Systems, 1994) was used to determine differences between treatments for the unbalanced data. Least square means and standard errors (s.e.) were calculated. The level of significance between least square means was tested with the Bonferroni test (Samuels, 1989). Average daily gain was analysed with the ANOVA model (Statistical Analysis Systems, 1994), and the significance of differences between means was determined using the Tukey t-test (Samuels, 1989). 


\section{Results}

Dry matter availability differed between treatments both at the beginning and end of each grazing period (Table 3). Figure 1 depicts the amount of dry matter available per sheep throughout the grazing period.

Table 3 Mean ( \pm s.e.) dry matter availability (t/ha) at the start (initial) and end (terminal) of each grazing period of $P$. maximum cv. Gatton

\begin{tabular}{lccc}
\hline & $\begin{array}{l}\text { High stocking rate } \\
\text { Quick rotation }(\mathrm{A})\end{array}$ & $\begin{array}{c}\text { Medium stocking rate } \\
\text { Medium rotation }(\mathrm{B})\end{array}$ & $\begin{array}{c}\text { Low stocking rate } \\
\text { Long rotation }(\mathrm{C})\end{array}$ \\
\hline Initial availability & $1.129^{\mathrm{a}}( \pm 0.14)$ & $2.558^{\mathrm{b}}( \pm 0.19)$ & $6.510^{\mathrm{c}}( \pm 0.27)$ \\
Terminal availability & $0.185^{\mathrm{a}}( \pm 0.05)$ & $1.409^{\mathrm{b}}( \pm 0.07)$ & $2.820^{\mathrm{c}}( \pm 0.10)$ \\
\hline
\end{tabular}

${ }^{\mathrm{a}, \mathrm{b}, \mathrm{c}}$ Row means with common superscripts do not differ significantly $(\mathrm{P}>0.05)$

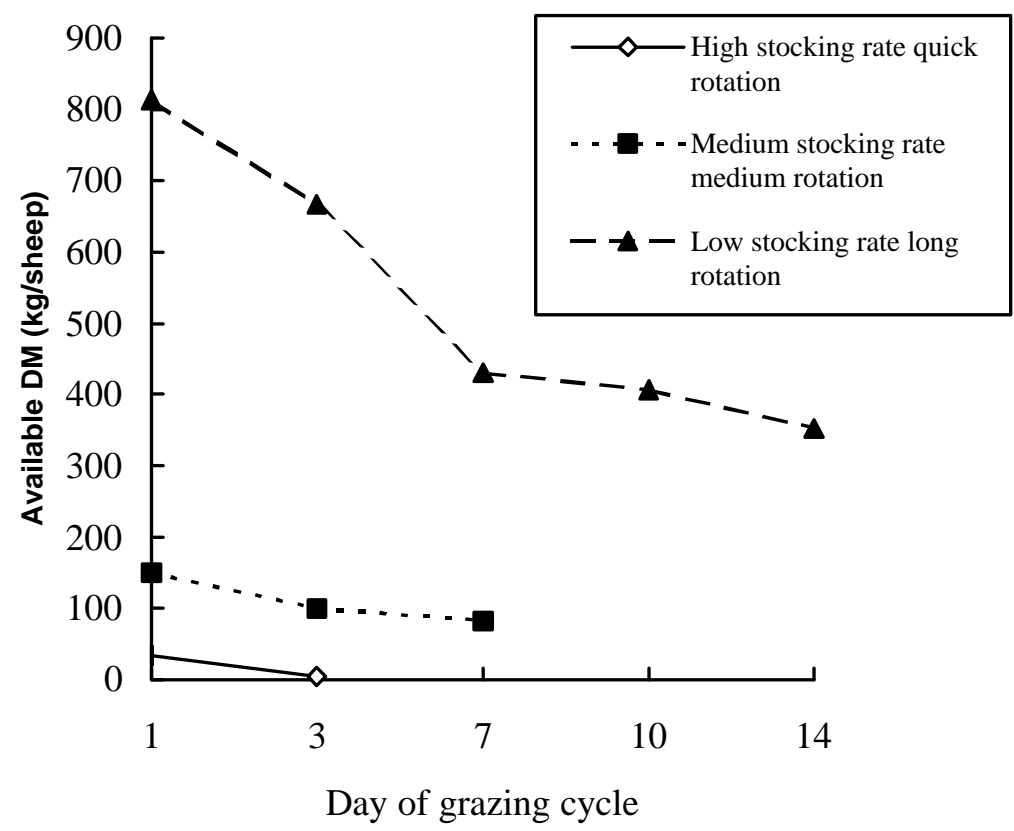

Figure 1 The amount of $P$. maximum $\mathrm{cv}$. Gatton dry matter (kg/sheep) available during the grazing period.

The opportunities for selection were very low in treatment A. At the end of the period of occupation only 5.61 $\mathrm{kg}$ DM per sheep was available for selection, in comparison with treatment $\mathrm{B}$, where $82.85 \mathrm{~kg}$ DM per sheep was available and treatment $\mathrm{C}$ where $352.5 \mathrm{~kg}$ DM per sheep was still available. The leaf to stem ratios at the start and end of each grazing cycle are shown in Table 4.

Table 4 Mean ( \pm s.e.) leaf to stem ratios during the grazing cycle of $P$. maximum cv. Gatton

\begin{tabular}{lccc}
\hline & $\begin{array}{c}\text { High stocking rate } \\
\text { Quick rotation }(\mathrm{A})\end{array}$ & $\begin{array}{c}\text { Medium stocking rate } \\
\text { Medium rotation }(\mathrm{B})\end{array}$ & $\begin{array}{c}\text { Low stocking rate } \\
\text { Long rotation }(\mathrm{C})\end{array}$ \\
\hline Initial ratio & $2.31^{\mathrm{a}}( \pm 0.25)$ & $2.39^{\mathrm{a}}( \pm 0.33)$ & $0.81^{\mathrm{b}}( \pm 0.47)$ \\
Terminal ratio & $0.07^{\mathrm{b}}( \pm 0.03)$ & $0.66^{\mathrm{a}}( \pm 0.04)$ & $0.17^{\mathrm{b}}( \pm 0.06)$ \\
\hline
\end{tabular}

${ }^{\mathrm{a}, \mathrm{b}, \mathrm{c}}$ Row means with common superscripts do not differ significantly $(\mathrm{P}>0.05)$

It is clear from Table 4 that the proportion of leaf was very low for treatment $\mathrm{C}$ both at the beginning and end of the period. The amount of leaf available per sheep over the grazing period is presented in Figure 2. 


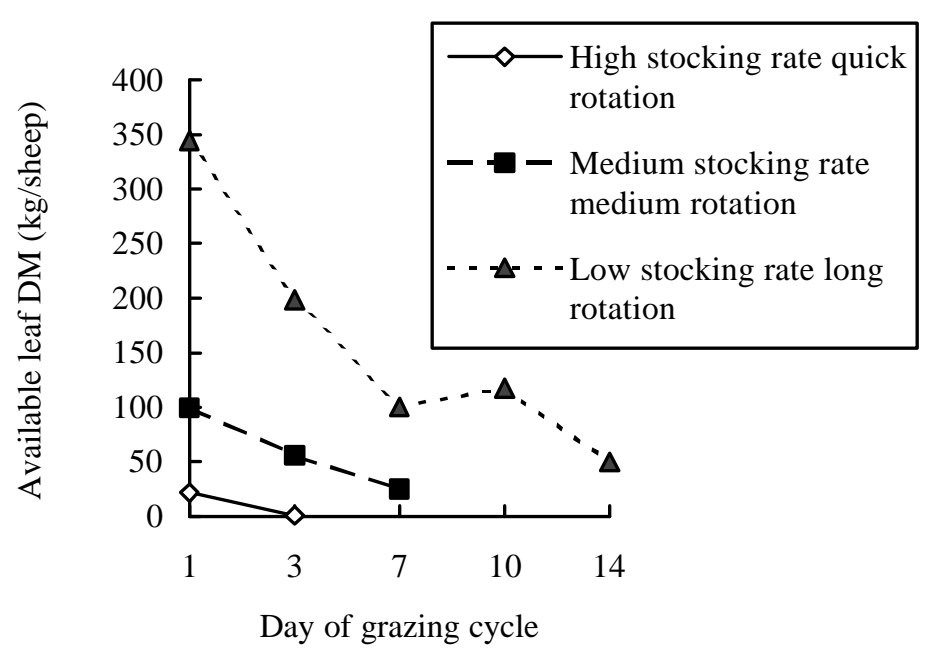

Figure 2 The amount of leaf available per sheep (kg/sheep) for P. maximum cv. Gatton grazed at various stocking rates

The amount of leaf available per sheep was highest for treatment $\mathrm{C}$ followed by treatment $\mathrm{B}$ and then treatment $\mathrm{A}$ at all stages in the grazing period (Figure 2). This differs from the trend shown in Table 4. Although the leaf:stem ratio was highest for treatment $\mathrm{B}$ at the end of the grazing period, the actual amount of leaf was much higher in treatment $\mathrm{C}$ than in treatment $\mathrm{B}$. The leaf:stem ratio did not differ between treatments $\mathrm{C}$ and $\mathrm{A}$ at the end of the grazing period, but if the amounts are compared it is clear that at the end of a grazing period $0.6 \mathrm{~kg}$ of leaf was available per sheep to select from for treatment A, compared to $50 \mathrm{~kg}$ for treatment $\mathrm{C}$.

Data on the height of the pasture, as measured with the pasture disc meter, are presented in Table 5 and livestock performance over the 72 day grazing period are presented in Table 6.

Table 5 Mean ( \pm s.e.) values for height of P. maximum cv. Gatton pasture $(\mathrm{cm})$

\begin{tabular}{lccr}
\hline & High stocking rate & Medium stocking rate & Low stocking rate \\
& Quick rotation $(\mathrm{A})$ & Medium rotation $(\mathrm{B})$ & Long rotation $(\mathrm{C})$ \\
\hline Initial height & $12.79^{\mathrm{a}}( \pm 0.98)$ & $30.38^{\mathrm{b}}( \pm 1.31)$ & $118.08^{\mathrm{c}}( \pm 1.83)$ \\
Terminal height & $2.74^{\mathrm{a}}( \pm 0.57)$ & $8.58^{\mathrm{b}}( \pm 0.75)$ & $79.25^{\mathrm{c}}( \pm 1.06)$ \\
\hline
\end{tabular}

${ }^{a, b, c}$ Row means with common superscripts do not differ significantly $(\mathrm{P}>0.05)$

Table 6 Effects of the high stocking rate, quick rotation treatment (A), medium stocking rate, medium rotation treatment (B) and a low stocking rate, long rotation treatment (C) on performance of sheep grazing $P$. maximum cv. Gatton. Values in parentheses denote standard deviations.

\begin{tabular}{cccc}
\hline & \multicolumn{3}{c}{ Treatment } \\
\cline { 2 - 4 } & $\mathrm{A}$ & $\mathrm{B}$ & $\mathrm{C}$ \\
\hline Live mass gain $(\mathrm{kg} / \mathrm{sheep})$ & 5.6 & 9.9 & 6.8 \\
Average daily gain $(\mathrm{g} / \mathrm{sheep})$ & $80^{\mathrm{a}}( \pm 15.53)$ & $140^{\mathrm{b}}( \pm 13.89)$ & $90^{\mathrm{a}}( \pm 30.44)$ \\
\hline${ }^{\mathrm{a}, \mathrm{b}, \mathrm{c}}$ Row means with common superscripts do not differ significantly $(\mathrm{P}>0.05)$
\end{tabular}

The production per ha over the 2.5 month period (mass gain x stocking rate) was $184.8 \mathrm{~kg} / \mathrm{ha}, 168.3 \mathrm{~kg} / \mathrm{ha}$ and $54.4 \mathrm{~kg} / \mathrm{ha}$ for treatments $\mathrm{A}, \mathrm{B}$ and $\mathrm{C}$ respectively.

\section{Discussion}

Although lighter stocking rates would be expected to yield better animal performance according to Tainton (1988), there were no differences in the average daily gains of animals for the high stocking rate compared to the low stocking rate, while animals from the intermediate stocking rate had the best ADG. This does not necessarily mean that these results contradict the above-mentioned theory, because there were factors other than stocking rate involved 
in this study (Table 2). Treatment A represents the high stocking rate treatment, but it also had the shortest period of absence of 17.5 days. Treatment B had an intermediate stocking rate with a period of absence of 35 days and treatment $\mathrm{C}$ had the lowest stocking rate with a period of absence of 70 days. The length of the re-growth period could also have influenced the results as available pasture, leaf to stem ratio and height of pasture all differed between treatments. It is possible that the high stocking rate (treatment A) depressed animal performance because animals did not have the opportunity to select, although this treatment had the shortest re-growth period and hence was characterised by high quality and low availability. At the start of a grazing cycle initial availability was lower for treatment $\mathrm{A}$ than for treatment $\mathrm{B}$, and both were lower than for treatment $\mathrm{C}$ (Table 3). This tendency was also evident at the end of a grazing period and is also illustrated in Figure 1. According to Jones et al. (1987) it is possible that intake can be restricted at high stocking rates because the pasture availability is limiting. At the same time the ability to select decreases and the average digestibility may also decline. Allden \& Whittaker (1970) have also noted that intake was relatively constant at a high dry matter availability, but intake was also depressed if the dry matter availability dropped below a certain level.

Treatments $\mathrm{A}$ and $\mathrm{B}$ had a higher leaf percentage than treatment $\mathrm{C}$ at the beginning of each grazing cycle; by the end of a grazing cycle the leaf percentage was lowest for treatments A and C, and highest for treatment B (Table 4). A higher intake of leaves than stems would be expected (Laredo \& Minson, 1973; McLeod et al., 1990). Although the initial leaf:stem ratio did not differ between treatments A and B, the actual amount of leaf available per sheep, from which to select, was much lower for treatment A than for treatment B (Figure 2). This trend was also very clear at the end of the period where the amount of leaf available was very low for treatment A ( $0.6 v s .25 .29$ and $343.75 \mathrm{~kg}$ leaf$/ \mathrm{sheep} \mathrm{for} \mathrm{treatments} \mathrm{B} \mathrm{and} \mathrm{C} \mathrm{respectively).} \mathrm{It} \mathrm{is} \mathrm{thus} \mathrm{evident} \mathrm{that} \mathrm{the} \mathrm{opportunity} \mathrm{for} \mathrm{selection} \mathrm{in}$ treatment A was very limited. Leaf material has the highest quality in the sward, and diet quality is strongly correlated with the amount of leaf in the diet (O'Reagain \& Mentis, 1988). The sward height was much lower for treatments $\mathrm{A}$ and $\mathrm{B}$ in comparison to treatment $\mathrm{C}$ both at the beginning and end of each grazing cycle (Table 5). O'Reagain et al. (1996) observed that sheep bite rates dropped with an increase in sward height. Increasing sward height is also related to a lower dietary quality (Chacon et al., 1978). Thus, treatment A had an advantage when compared to treatment $\mathrm{C}$ in terms of sward height.

The evidence indicates that although treatment $\mathrm{A}$ represented a much younger and shorter pasture than treatments B or C, the animals had less dry material to select from. This possibly explains the poorer performance of sheep on this treatment. This is also reflected in the lower leaf percentage at the end of a grazing cycle in treatment A compared to treatment B. The superior performance of treatment B may be the result of a combination of stocking rate and re-growth period. Treatment $\mathrm{B}$ had a lower stocking rate than treatment $\mathrm{A}$ and a shorter re-growth period than treatment $\mathrm{C}$.

The dry matter availability for treatment B was intermediate between those for treatments A and C, both at the beginning and end of a grazing cycle (Table 3). Treatment B had a higher initial leaf percentage than treatment $\mathrm{C}$, but leaf percentage did not differ from treatment A (Table 4). At the end of a grazing cycle treatment B had the highest leaf percentage. In spite of this superior leaf:stem ratio for treatment $\mathrm{B}$, the actual amount of leaf available per sheep was less than for treatment $\mathrm{C}$, although much more than for treatment A. The animals allocated to treatment B had $25.29 \mathrm{~kg}$ leaf per sheep to select from, which was much more than the value of $0.6 \mathrm{~kg}$ leaf per sheep for treatment $\mathrm{A}$ at the end of a cycle, and could explain the better performance of treatment B compared to treatment A. Although treatment $\mathrm{C}$ had a much higher production of leaf than treatment $\mathrm{B}$, the animals did not perform better, which suggests that the amount of leaf available to select from is not the only factor involved. Treatment $\mathrm{C}$ had a significantly higher dry matter availability at the beginning and end of each grazing cycle. This is reflected in Figure 1 which shows that dry matter availability per sheep was high throughout the grazing period. Dry matter availability, therefore, can be eliminated as one of the factors that resulted in poorer results for this treatment. Treatment $\mathrm{C}$ had a much lower leaf percentage than the other two treatments at the beginning of a grazing cycle. At the end of a cycle, treatment $\mathrm{A}$ and $\mathrm{C}$ had the same leaf percentage, which corresponds with the lower animal performance on both these treatments (Table 6). O'Reagain et al. (1996) noted that sheep bite rates decline with an increase in the proportion of stems because animals continue to select leaf in such a sward. A high stem content may restrict access to leaves, forcing animals to consume lower quality dead or partly senescent herbage. Although treatment $\mathrm{C}$ had a low leaf percentage, the amount of leaf per sheep was much higher than for the other two treatments. It is thus possible that pasture structure played a more important role than the actual amount of leaf. The height of pasture in treatment $\mathrm{C}$ was much higher at the start of a grazing cycle compared to the other treatments (Table 5). Dietary quality is usually negatively correlated with sward height during the growing season (Chacon $e t$ 
al., 1978). Leaf quality also declines with increasing height due to increased lignification with increasing age (Wilson \& t'Mannetje, 1978). It is concluded that the poor performance for treatment $\mathrm{C}$ was probably caused by the longer regrowth period. This resulted in a low quality pasture despite a high dry matter availability and a lower stocking rate which gave the animals opportunity to select. The accumulation of unused herbage in treatment $\mathrm{C}$ towards winter could also have had an adverse effect on animal production.

In terms of livestock production per hectare, treatment A had the highest production followed by treatment $\mathrm{B}$. Production per hectare was much lower for treatment $\mathrm{C}$ compared to treatments $\mathrm{A}$ and $\mathrm{B}$. This corresponds with results suggesting that production per hectare increases with increasing stocking rate up to a certain point, after which it declines (Hart et al., 1988; Heitschmidt et al., 1990; Bryan \& Prigge, 1994). It is evident that the point at which gain per hectare begins to decline was not reached within the range of stocking rates used in this experiment. Although treatment A gave the highest production per hectare, it must be noted that animals were lighter than for treatment $\mathrm{B}$ and had a much poorer average daily gain. This would result in animals that would take a much longer time to reach a marketable weight than the animals in treatment B which were heavier and had a higher average daily gain.

\section{Conclusions}

It is concluded that a stocking rate of 17 sheep per hectare and a re-growth period of 35 days would give the best results in terms of animal performance for P. maximum cv. Gatton pastures cultivated under local dryland conditions. In terms of production per hectare, the highest stocking rate yielded the highest production per hectare. The stocking rate was, however, still below the point at which production per hectare would begin to decline.

\section{References}

Allden, W.G. \& Whittaker, I.A.McD., 1970. The determinants of herbage intake by grazing sheep: The interrelationship of factors influencing herbage intake and availability. Aust. J. Agric. Res. 21, 755.

Bransby, D.I. \& Tainton, N.M., 1977. The disc pasture meter: Possible applications in grazing management. Proceedings of the Grassland Society of Southern Africa. 12, 115.

Bryan, W.B. \& Prigge, E.C., 1994. Grazing initiation date and stocking rate effects on pasture productivity. Agron. J. 86, 55.

Chacon, E.A., Stobbs, T.H. \& Dale, M.B., 1978. Influence of sward characteristics on grazing behaviour and growth of Hereford steers grazing tropical grass pastures. Aust. J. Agric. Res. $29,89$.

Hart, R.J., Samuel, M.J., Test, P.S. \& Smith, M.A., 1988. Cattle, vegetation and economic responses to grazing systems and grazing pressure. J. Range Mng. 41, 282.

Heitschmidt, R.K., Conner, J.R., Canon, S.K., Pinchak, W.E., Walker, J.W. \& Dowhower, S.L., 1990. Cow/calf production and economic returns from yearlong continuous, deferred rotation and rotational grazing treatments. J. Prod. Agric. 3, 92.

Jones, R.M., Tothill, J.C. \& Jones, R.J., 1987. Pasture management in the Tropics and Sub-Tropics. Watson Ferguson \& Co., Brisbane.

Laredo, M.A. \& Minson, D.J., 1973. The voluntary intake, digestibility, and retention time of the leaf and stem fractions of five grasses. Aust. J. Agric. Res. 24, 875.

McLeod, M.N., Kennedy, P.M. \& Minson, D.J., 1990. Resistance of leaf and stem fractions of tropical forage to chewing and passage in cattle. Br. J. Nutr. 63, 105.

Meissner, H.H., Hofmeyr, H.S., Van Rensburg, W.J.J. \& Pienaar, J.P., 1983. Classification of livestock for realistic prediction of substitution values in terms of biologically defined Large Stock Unit. Technical Bulletin No. 175, Department of Agriculture, South Africa.

Minson, D.J., 1971. The nutritive value of tropical pastures. J. Aust. Inst. Agric. Sci. pp. 255.

O`Reagain, P.J. \& Mentis, M.T., 1988. Seasonal changes in the quality of diet selected by cattle grazing the Natal Sour Sandveld. J. Grassl. Soc. S. Afr. 5, 48.

O'Reagain, P.J., Goetsch, B.C. \& Owen-Smith, R.N., 1996. Effect of species composition and sward structure on the ingestive behaviour of cattle and sheep grazing South African Sourveld. J. Agric. Sci., Camb. 125,127.

Pieterse, P.A., Rethman, N.F.G., \& Van Bosch, J., 1994. Die invloed van N-peil, grondtipe en waterstremming op die produksie en watergebruiksdoeltreffendheid van Panicum maximum cv. Gatton.

Samuels, M.L., 1989. Statistics for the life sciences. Collier Macmillan Publishers, London. 
(C) South African Society of Animal Science

Statistical Analysis Systems, 1994. SAS User's Guide: 1994. Statistics Version 6. SAS Institute Inc. Cary, NC., USA.

Tainton, N.M., 1988. Veld and pasture management in South Africa. 2nd Ed. Shuter and Shooter, Pietermaritzburg.

Waddington, J. \& Cook, D.A., 1971. The influence of sample size and number on the precision of estimates of herbage production and consumption in two grazing experiments. J. Br. Grassl. Soc. 26, 95.

Wilson, J.R. \& t'Mannetje, L., 1978. Senescence, digestibility and carbohydrate content of Buffel grass and Green Panic leaves. Aust. J. Agric. Res. 29, 503. 